\title{
FACTORES DE RIESGO Y PROTECCIÓN EN AGRESIÓN INFANTIL RISK AND PREVENTIVE FACTORS OF CHILD AGGRESSION
}

\author{
V. DEL BARRIO GÁNDARA y M.L. RoA CAPILlA \\ Facultad de Psicología. Universidad Nacional de Educación a Distancia (UNED)
}

\section{Resumen}

Se exponen los factores de riesgo que han sido considerados como los más relevantes para explicar la aparición de la agresión en niños y adolescentes (biológicos, personales, familiares y sociales). Con ello se asientan las bases para poder construir los planes de prevención que pueden evitar la aparición de las conductas agresivas que hoy tienen una incidencia tan alta y preocupante, tanto para la familia como para la sociedad.

\section{Palabras Clave}

Factores de riesgo, factores protectores, agresión, niños

\begin{abstract}
This paper presents the most important risk factors behind aggressive children and adolescent: biological, personal, family and social factors. The data obtained contribute to the confection of prevention plans for inhibition the hit rate of these problems. Children and adolescent aggression is the mayor family and social concern.
\end{abstract}

\section{Key Words}

Risk factors, preventive factors, aggression, children 


\section{Introducción}

Parece evidente que la violencia en los niños y adolescentes ha sufrido un incremento en los últimos tiempos. Las estadísticas llevadas a cabo en los Estados Unidos detectan este aumento, cuantificado objetivamente, desde los años ochenta. Este fenómeno lo percibe también el hombre de la calle a través de los medios de comunicación que nos informan cada día de sucesos agresivos perpetrados por niños. No es raro que en institutos de segunda enseñanza se produzcan conductas de ataque, por grupos de preadolescentes, contra compañeros y profesores. Lo más alarmante son las muertes que se han producido en las escuelas; las más espectaculares en los EE.UU, donde adolescentes armados con pistolas o rifles han asesinado a compañeros y maestros. De igual manera, hay un incremento de la violencia contra indigentes e inmigrantes y, en general contra personas que están indefensas ante estos grupos violentos, que los atacan sin ningún escrúpulo. Pensábamos que era algo que ocurría en otras culturas, pero ya lo tenemos en casa. Comenzó a perfilarse con crudeza hace unos 10 años, pero las cosas van en aumento: los chicos de Alcacer que abusaron salvajemente y mataron a dos chicas; el chico de la catana que asesinó a sus padres y hermana; Raquel e Iría que, por curiosidad de qué se sentía al matar, lo hicieron con su compañera de curso; el suicidio de Jokin; por el acoso al que lo sometieron sin piedad sus compañeros. Más recientemente un grupo de chicos quemaron a una mujer sin techo en un cajero; el apuñalamiento de un compañero en un patio de recreo en Bilbao; la agresión a una niña en un colegio de Badajoz; el niño apaleado por sus compañeros en Barcelona; un alumno que ataca a su profesor en Córdoba; los niños de Hospitalet que pegaban a transeúntes para filmar sus caras; los niños de Sevilla que vejaron y maltrataron a una niña con síndrome de Down; y otros casos que confirman una alargada lista, cuyos protagonistas son adolescentes. Por otra parte, crecen las asociaciones de víctimas: de padres agredidos por sus hijos (1\%), de profesores amenazados, de niños acosados por sus compañeros, lo cual es un síntoma añadido más de que la violencia crece. Además aparece un nuevo tipo de violencia lúdica y gratuita que es quizás la forma más repugnante de toda clase de violencia.
Se ha venido cuantificando la violencia infantil con precisión desde los años ochenta. Pfeiffer (2004), especialista en el tema sostiene que en Suiza el incremento se sitúa entre un 100 y un 50 por cien. El mismo autor estima que en España, la subida alcanza un 50\%. Las cifras oficiales en nuestro país admiten un incremento del $10 \%$ de faltas y un $10 \%$ de delitos por lesiones en la población general. Pero esto sólo afecta a los casos que terminan en un proceso legal. También es verdad que las cifras de asesinatos permanecen estables, e incluso bajan en países donde se ha gastado mucho dinero en prevención, como ocurre en los Estados Unidos.

La violencia, la agresividad, el vandalismo, la delincuencia son síntomas de una socialización inadecuada, puesto que en ella priman las motivaciones individuales frente a las sociales. Todo ello es especialmente preocupante puesto que, un comportamiento excesivamente agresivo en la infancia, predice la agresividad durante la adolescencia y la edad adulta, y si esto no fuera suficiente, la existencia de patologías alcanzada la madurez. Este hecho ya justifica sobradamente el que se preste especial atención a las manifestaciones de agresividad durante el periodo que dura la socialización del niño.

Desde un punto de vista teórico es ya clásica la teoría de Dollar et al. (1939) según la cual la agresión se explica como una conducta instintiva y también aprendida, nacida como resultado de la frustración. Lo instintivo tendría su asiento en estructuras biológicas, lo aprendido en el sistema de valores trasmitido.

Al final, el desencadenante concreto de la agresión vendría a ser la frustración que se produce circunstancialmente, cuando no se alcanzan las metas personales o sociales deseadas.

Recientemente Beck (2003) ha tratado de explicar la agresión desde dos tipos de emociones, la ira y la hostilidad. Otras explicaciones las podemos encontrar en Spielberger, et al. (1988), quien puso especial énfasis en el egoísmo y los pensamientos, y en autores como Bandura (1973), que destacó los aspectos sociales.

Es decir que la agresión hoy, si unimos estas explicaciones teóricas, vendría a constituir un modelo tripartito: biológico, etológico y ecológico. Habría unas estructuras orgánicas indivi- 
duales (organismo), unos patrones de comportamiento (instinto) y un aprendizaje de modos de expresión e inhibición de la conducta agresiva que emanan de la sociedad (cultura).

Veamos con más detalle cada uno de estos aspectos.

\section{Factores somáticos o biológicos}

Aunque no nos vamos a centrar en las bases biológicas de la agresividad, nos referiremos aquí a los que se han considerado los más importantes factores de este tipo tanto funcionales (hormonales, neurales) como estructurales. Estos últimos son los más conocidos y tienen una clara secuencia causal. Las malformaciones, lesiones cerebrales traumáticas, especialmente en la zona orbitofrontal, poseen una relación claramente conocida con algunas formas de agresividad (Roussy y Toupin, 2000). Hay otras razones de tipo acumulativo que pueden producir alteraciones estructurales como la mala nutrición, problemas de salud específicos o el estrés producido por el maltrato. Todos ellos pueden provocar transformaciones en las estructuras prefrontales, cuerpo calloso y sus conexiones límbicas, e incluso, en el tamaño del hipocampo y en el uso asimétrico de los hemisferios. Esas transformaciones se asocian a la aparición de comportamientos agresivos de mayor o menor intensidad y con difícil solución (Teichener, 2004).

Es interesante, desde una perspectiva infantil, comprobar que este tipo de alteraciones actúan con mucha más fuerza en el período precoz de crecimiento acelerado, parece que la relación afectiva con la madre acelera el desarrollo del vermis; incluso, como ya había advertido Harlow, los monos separados de sus madres se vuelven agresivos y parece ser que, si esa condición no se da, el desarrollo cerebral progresa adecuadamente (Prescot, 1980).

Respecto a las alteraciones de tipo funcional la secuencia no está tan clara. Hay un problema de antes y después de difícil determinación. De hecho puede darse el caso de que una alteración hormonal pueda producir agresión o, por el contrario, que los acontecimientos del entorno provoquen un desajuste de los niveles hor- monales o de los desequilibrios en los neurotransmisores. Este carácter interactivo de lo biológico y lo psíquico, hoy vigente, se viene señalando desde hace tiempo (Akiskal y McKinney, 1975) Así, las relaciones entre agresividad y hormonas es un tema controvertido en el desarrollo del niño. La relación entre ellas se puede establecer en tres direcciones: las hormonas pueden estar implicadas en el desarrollo de la agresión como causa, como consecuencia o como mediador (Martín Ramirez, 2003). Siempre se ha relacionado la testosterona con la agresión, sin embargo cada vez hay más constancia de que el papel social de género incrementa las respuestas agresivas de los varones que se ven frecuentemente avocados a ellas.

Con respecto a los neurotransmisores encontramos el mismo problema, de forma que el concepto interactivo entre contexto y respuesta se va constituyendo como la más potente explicación. Fundamentalmente, la tesis vigente es que se trata de una función complementaria: una activación del sistema dopaminérgico junto a una inhibición del serotonérgico.

Un estudio con metaanálisis muestra que los grupos de sujetos con conductas antisociales presentan bajos niveles de serotonina en el fluido cerebroespinal. Concretamente, con el metabolito de la serotonina 5 HIAA (ácido hydroxyindoleacetic). Esto se halla modulado por la edad, ya que los sujetos menores de 30 años presentan más agresión que los mayores (Moore, Scarpa y Raine, 2002).

Esa interacción entre contexto y respuesta neural se muestra en la activación del sistema dopaminérgico así como en la inhibición funcional del sistema serotonérgico, lo cual se confirma en los estudios realizados sobre ganadores que compiten bajo la influencia de la experiencia repetida de agresión. El desarrollo de agresión aprendida a través del reforzamiento de la agresión por la victoria tras periodos de confrontación fortalece la conducta agresiva y decrece la emocionalidad. Situaciones estresantes provocan incrementos en agresión (Kudryavtseva, 2000).

En cualquier caso, los excesos de las sinapsis durante la adolescencia temprana y la primacía del sistema límbico sobre el neocortex en si- 
tuaciones emocionalmente cargadas, pueden llevar al incremento de la agresión (más en chicos que en chicas). En la adolescencia tardía, la poda sináptica y el incremento del procesamiento neocortical de situaciones cargadas emocionalmente pueden permitir al adolescente llegar a ser más racional en situaciones inductoras de emoción negativa y a elegir vías alternativas a la agresión (Yurgelun-Todd, 1998; Brownlee, 1999; Spear, 2000; citados en Kirsh, 2003)

Todo ello constituye la base física de la agresión y regula lo que los etólogos han llamado conducta de defensa básica (Lorenz, 1966) que compartimos con los animales; pero la agresión humana es mucho más compleja.

\section{Factores Personales}

Dejando a un lado las bases biológicas, las características de un joven violento, según del Barrio (2003), serían las siguientes: sexo masculino, temperamento difícil, alta impulsividad, poco autocontrol, poca autoeficacia, deficientes lazos afectivos y bajo rendimiento escolar. Muchas de estas características conforman el núcleo de lo personal y tienen carácter natural y también artificial.

\section{Sexo}

Las primeras manifestaciones de rabia y frustración en los bebés son similares en ambos sexos, pero las diferencias entre ellos emergen muy precozmente en lo que se refiere a la agresividad instrumental (Loeber y Hay, 1997; Loeber y Stouthamer-Loeber, 1998), no sólo en la cantidad, sino especialmente en su calidad. Puesto que muchos estudios han señalado una mayor agresividad en los varones (Maccoby y Jancklin, 1980; Hyde, 1984; Caprara y Pastorelli, 1993; Pastorelli, Barbaranelli, Cermak, Rozsa y Caprara, 1997), las diferencias se modulan cuando se estudian los diferentes tipos de agresión (Crick y Grotpeter, 1995; Crick, Casas, y Mosher, 1997; Galen y Underwood, 1997). La media de diferentes datos es que, en episodios policiales asociados a la violencia, hay una proporción de 9/1 entre varones y mujeres, estas diferencias se han querido explicar a través de modelos biológicos, modelos de socialización parental diferencial, así como por el aprendizaje observacional (Bandura, 1973; Maccoby y Jacklin 1980).

Estos modelos aportan diferencias respecto a las formas de agresividad en niños y niñas (Bjorkquist, Lagerspetz y Kaukiainen, 1992). Las niñas parecen manifestar conductas agresivas indirectas o relacionales y los niños conductas de agresión directa o abierta. El modelo de las representaciones sociales (Campbell y Muncer, 1994; Campbell, Sapochnik Muncer, 1997), sostiene que niños y niñas difieren en este aspecto que contiene, a su vez, atribuciones y actitudes distintas que son transmitidas por la cultura. Loeber y Stouthamer-Loeber (1998) sugieren que las diferencias de género en la conducta agresiva, puede ser explicada por el umbral diferencial de niños y niñas a la exposición de factores de riesgo, dado que varones y hembras se enfrentan a distintas exigencias que pueden conducirles a diferentes formas de expresión de la agresión; por ejemplo, las mujeres podrían manifestar conductas agresivas, sólo cuando son expuestas a un mayor número de elementos de riesgo que los hombres.

En población adolescente española se han encontrado en algún caso mayores puntuaciones de agresión en las chicas (Lemos et al., 1992), pero suele ser agresión verbal.

Algunos estudios han señalado que las diferencias sexuales en agresividad no son tales si se contemplan las distintas formas de agresividad. Crick y Grotpeter (1995) encuentran que, tanto chicas y chicos entre 9 y 12 años, muestran similares puntuaciones globales en agresión; no obstante, la conducta agresiva relacional es más alta en las mujeres que en los hombres (Crick y Grotpeter, 1995). Este tipo de agresión se relaciona con niveles altos de rechazo de iguales, soledad, depresión y aislamiento; y con estos mismos resultados se han encontrado niños de 3 a 4,5 años (Crick et. al.,1997).

Aunque las diferencias en la conducta agresiva directa tienden a desaparecer en la edad adulta (Campbell, Sapochnik y Muncer, 1997), ya desde la adolescencia las mujeres continúan manteniendo mayor agresividad expresiva indi- 
recta (descarga de ira) que los hombres (Galen y Underwood, 1997).

También se han encontrado diferencias en el destinatario de la agresión, en chicos y chicas con edades entre 10 y 13 años, las chicas suelen utilizar más agresión social contra las chicas, mientras que los chicos tienden a usar la agresión física contra los chicos.

Las chicas son más agresivas si se trata de agresividad indirecta (hablar mal de los otros, excluir a compañeros...). Esto se puede explicar por el deseo de las chicas por crear relaciones más emocionales, intimas o cerradas, lo que parece predisponerlas a la victimización.

En ocasiones se ha buscado una explicación evolutiva a las diferencias de género en la agresión, bien en función del momento en que comienza la conducta agresiva, bien en función del desarrollo sobre el tiempo de la misma. En este sentido, cabe matizar que las chicas desarrollan conductas antisociales más frecuentemente durante la adolescencia en comparación con los chicos, cuya agresividad se desarrolla en edades más tempranas (Loeber y Stouthamer- Loeber 1998).

Estudiando la agresividad física verbal e indirecta en cuatro países (Finlandia, Israel, Italia y Polonia) entre sujetos de 8, 11 y 15 años, las chicas usaban principalmente la agresión indirecta, en segundo lugar, la agresión verbal y, por último, la agresión física. Entre los chicos la agresión indirecta era el estilo menos usado en todas las edades. La agresión física y verbal era en los chicos igualmente usada a la edad de los 8 y 11 años, mientras que, a la edad de 15 años, la agresión verbal superaba la agresión física y era el estilo más usado. Los varones toman como blancos, en mayor medida, a otros varones para la agresión directa, pero el género no se relaciona con tomar como objetivo un chico o una chica para emitir una agresión indirecta. (Österman, Björkqvist, Lagerspetz, 1999)

\section{Temperamento y Agresividad}

Si partimos de una definición de temperamento podemos contemplar en ella los distintos elementos que lo constituyen.
"El temperamento se refiere a fenómenos de naturaleza emocional característicos de un sujeto que incluyen su susceptibilidad ante los estímulos emocionales, la fuerza de sus hábitos, la rapidez de sus respuestas, la calidad de su talante, ánimo o afecto (mood) y todas las peculiaridades de la fluctuación e intensidad del ánimo; estos fenómenos se consideran como dependientes de la constitución y de origen hereditario" (Allport, 1937).

El estudio del temperamento infantil se inicia con Fries (1937). Éste se dedicó a la observación de las diferencias que se hacían patentes en las conductas de niños recién nacidos. Ello le permitió una primera clasificación en dos tipos temperamentales: 1) niños con alta actividad congénita, y 2) niños de baja actividad congénita. Thomas, Chess y Birch (1968) llegaron a las mismas conclusiones. Según un estudio realizado por estos autores se encontraron también: 1) niños de temperamento difícil (alta actividad-bajo acercamientopoca ritmicidad); 2) niños de temperamento fácil de características opuestas y 3) niños de temperamento mixto.

Por su parte Buss (1995), resume toda la investigación sobre el tema diciendo que las características fundamentales del temperamento son: la emocionalidad (capacidad de reacción afectiva), la actividad, (entendida como nivel de arousal), la sociabilidad, (preferencia por la compañía), y la impulsividad, (tendencia a responder sin reflexión). Como es evidente la agresión se halla íntimamente unida a los procesos de emocionalidad, actividad e impulsividad.

El temperamento difícil, que aparece constantemente ligado a la agresión, se caracteriza por un alto nivel de actividad e impulsividad normalmente asociado con problemas de agresión e hiperactividad (Schaughency y Fagot, 1993). Concretamente, la impulsividad correlaciona fuertemente con "Trastornos de conducta”, es decir, trastornos de tipo exteriorizado que, normalmente, se asocian a agresión o a otras conductas que implican riesgo de cometer conductas agresivas (sexo, drogas, la conducción peligrosa) y que manifiestan una deficiencia de la conducta autorregulatoria (Wills, Sandy y Yaeger 2000). 
Aunque se considera que el temperamento está determinado biológicamente, sin embargo, existen varias posiciones. Para Baumrind (1993), el ambiente puede actuar sobre el temperamento difícil del niño, pudiendo los padres influir en esta característica a través de un estilo educativo que incluya el razonamiento, las estrategias de disciplina adecuadas y la comunicación persuasiva. Si asumimos que el temperamento difícil es un factor de riesgo para el desarrollo de problemas, su impacto dependerá de la calidad del modelo educativo que proporcionan los padres. Rutter (1987), señala que el temperamento no es inmutable, los padres que son sensibles a las necesidades de sus hijos sirven de escudo protector a la vulnerabilidad del hijo. Para Belsky (1991) el temperamento del niño puede ser influido por los padres, tanto de forma positiva como negativa. Esto es lo que los autores llaman personalidad, que consiste en la interacción entre temperamento y ambiente.

\section{Personalidad}

Actualmente, podría decirse que existen dos grandes modelos de estructura de personalidad: el de tres dimensiones postulado por Eysenck (1975) (Neuroticismo, Extroversión y Psicoticismo) o el más reciente de los cinco grandes: Cordialidad, Apertura, Neuroticismo, Extroversión y Conciencia, denominado modelo instrumental (McCrae y Costa, 1991). En ambos se encuadran la extroversión y el neuroticismo, que son consideradas las estructuras básicas con las que constantemente se relacionan la violencia y la agresión. La base empírica de esta relación está bien fundada en numerosos estudios (del Barrio et al., 2001).

La aproximación a la agresividad desde el estudio de la personalidad ha sido abordada extensamente por Caprara y sus colaboradores (Caprara y Pastorelli, 1989; Caprara, Barbaranelli y Comrey, 1992; Caprara, Manzi, Perugni, 1992; Bandura, Barbaranelli, Caprara y Pastorelli, 1996; Caprara, Barbaranelli y Zimbardo, 1996).

Por una parte, la extroversión propicia unas formas de vida en donde la conducta violenta florece con más probabilidad al darse las características siguientes: a) búsqueda de sensaciones, b) baja percepción del riesgo o daño, c) baja capacidad para diferir la gratificación.

Eysenck defendía que sus tres dimensiones estaban relacionadas con la conducta delincuente: la alta extraversión hace que los sujetos sean más difíciles de condicionar y, consecuentemente, tengan más dificultades en la inhibición de sus tendencias antisociales, al tiempo que por su baja activación cortical, buscan nuevas situaciones estimulantes. Con relación al neuroticismo, esta dimensión no ha sido especialmente importante para la delincuencia entre los más jóvenes.

No obstante, los sujetos con valores altos en neuroticismo, muestran mayores conductas antisociales dado el efecto multiplicador que la ansiedad ejerce sobre las conductas o impulsos, incrementando el motivo (drive) dominante.

Por último, el alto psicoticismo resulta en un aumento de la propensión a conductas delictivas, a causa de su reducida sensibilidad hacia los sentimientos de las personas y de su falta de culpa.

Estas dimensiones están todas relacionadas con una base neurológica. En apoyo a la relación entre delincuencia y activación (sustrato biológico de la extroversión) figuran los resultados hallados por Coren (1999), sobre 754 universitarios quienes completaron una medida de activación y otra relativa a sus conducta delictivas o antisociales durante su escolaridad como adolescentes. Consistente con la hipótesis de Eysenck, los chicos y chicas con menores niveles de arousal se implicaron en un mayor número de actividades delictivas o antisociales durante sus años escolares.

Los resultados de los estudios sobre la combinación entre extraversión y neuroticismo son algo más confusos. Mientras que Eysenck defendía que la extroversión y el neuroticimo eran predictores de la delincuencia en diferentes grados (Eysenck y Gudjonsson, 1989), otros estudios no han encontrado relaciones entre la combinación de puntuaciones altas en estas variables y la conducta delincuente (Furnham y Thompson, 1991). 
Heaven (1993), a propósito de las dimensiones de personalidad de Eysenck, encuentra que el psicoticismo es el mejor predictor de la delincuencia, frente a las otras dimensiones de extraversión y neuroticismo. El psicoticismo se consideró como un elemento mediador de ciertos factores de la comunicación familiar (Heaven, 1994) o como elemento que dificultaba el control del temperamento y la conducta de obedecer (Furnham y Gunter, 1983). Estos autores realizan una aproximación multidimensional a la agresividad, considerando tanto sus aspectos interpersonales, personales como contextuales. Dentro de este marco, examinan las diferencias individuales o dimensiones de la personalidad como constructos hipotéticos o estructuras afectivo-cognitivas que se desarrollan durante la ontogénesis y que constituyen variables mediadoras de la agresividad.

En los estudios llevados a cabo con los nuevos factores, los Cinco Factores, los hallazgos son parecidos: los jóvenes violentos tienen niveles más bajos de Conciencia y Cordialidad (John et al., 1994).

Un estudio posterior de Heaven (1996) estudió la relación entre delincuencia autoinformada y los Cinco factores de personalidad del NEO (McCrae y Costa, 1991) en una muestra de 216 adolescentes de 17 años de edad media. Sus resultados muestran que las variables de personalidad que se relacionan con la delincuencia son la agradabilidad, la conciencia y el neuroticismo; las dos primeras correlacionaron negativamente con la escala de vandalismo, pero la agradabilidad correlacionó además con la escala de violencia interpersonal. El neuroticismo se relacionó con la delincuencia, modulado por el sexo, de manera que se vinculó con la violencia interpersonal entre las mujeres y con el vandalismo entre los hombres.

La agresividad social o el maltrato entre iguales conocida como bullying (matonismo) (hostigamiento o agresividad social que, de forma reiterada, se dirige a determinados menores denominados víctimas, normalmente en el contexto escolar) ha sido también estudiada con relación a la personalidad entre escolares (Slee y Rigby, 1993; Mynard y Joseph, 1997). Ambos estudios, encontraron que los sujetos agresores (bullies) puntuaban alto en psicoticismo, y los sujetos agredidos (víctimas) bajo en extraversión, pero difirieron en sus resultados sobre neuroticismo. Mientras que los primeros no encontraron diferencias para esta dimensión de personalidad, los segundos encontraron que tanto los agresores (bullies) como los agredidos (víctimas) presentaban altas puntuaciones en neuroticismo.

En población española también se ha encontrado esta asociación con los cinco grandes, los niños más agresivos obtienen bajas puntuaciones en Cordialidad y Conciencia (Tur et al., 2004), por el contrario hay una correlación positiva entre Neuroticismo y conducta violenta tanto en adultos (Sobral et al., 2000) como en niños (del Barrio et al., 2001). La conducta agresiva, por tanto, siempre aparece positivamente relacionada con los factores de Neuroticismo, Extraversión, Psicoticismo, mientras que, por el contrario, se muestra negativamente correlacionada con Conciencia, Cordialidad, y Apertura.

Otros constructos personales han sido igualmente relacionados con la agresividad. Por ejemplo, Caprara, Barbaranelli, Comrey (1992) y Caprara, Manzi y Perugini (1992), encuentran cuatro constructos indicativos de agresividad: la susceptibilidad emocional, la irritabilidad, la rumiación y el sentimiento de culpa.

Williams (1990) no halló correlaciones significativas entre ninguna de las dimensiones de personalidad de Eysenck e ira, sin embargo cuando controla el efecto de la extraversión en el neuroticismo, encuentra que la extraversión correlaciona negativamente y de forma significativa con la ira. En un estudio anexo Heaven, en una muestra con adolescentes, recogió una medida de ira rasgo encontró que ésta se relacionaba sólo en los varones directamente con la conducta delictiva, e indirectamente, a través de la sociabilidad y el psicoticismo de Eysenck. En las mujeres, a pesar de no darse diferencias en las puntuaciones de ira respecto a los hombres, no apareció esta relación. En los grupos combinados de neuroticismo y extraversión, observa que el grupo caracterizado por alto neuroticismo e introversión presenta mayores niveles de ira que el grupo correspondiente a alto neuroticismo y extraversión (NI ( NE, similarmente aunque con significación marginal 
los sujetos neuróticos introvertidos superaban en ira a los introvertidos emocionalmente estables NI ( SI). La explicación de ello puede ser que los sujetos que muestran sus emociones no llegan a la acción y los que las reprimen sí.

Para Gray (1991) las conductas delictivas se producen más fácilmente en sujetos con una baja sensibilidad al castigo y una alta sensibilidad al refuerzo.

Inicialmente Eysenck y Eysenck (1963) describieron la extraversión con dos componentes, el de sociabilidad y el de impulsividad, sin embargo, los elementos de impulsividad fueron posteriormente eliminados, y esta característica, entendida como la responsable de las conductas disruptivas, quedó recogida en la dimensión de psicoticismo (Eysenck, Eysenck y Barrett, 1985), siendo para algunos autores la alta sociabilidad la responsable de la conducta delincuente en los adolescentes (Eysenck y Gudjonnsson, 1989).

Como han mostrado los estudios revisados, se puede concluir que tanto la agresividad como la ira, se han relacionado con las distintas características de personalidad, de forma no azarosa. De manera consistente, especialmente la agresividad, se han conectado con elevadas características de neuroticismo, alta extraversión, baja agradabilidad y baja conciencia, o similarmente, con altas características de la dimensión de psicoticismo de Eysenck.

Además de todo lo visto hay parámetros de la personalidad que se asocian estrictamente a la conducta agresiva, como los que siguen.

\section{Impulsividad}

La impulsividad es entendida como un concepto multidimensional que incluye dificultades en la contención de la conducta, manejo de emociones, (particularmente sexuales y agresivas), procesamiento rápido de la información, búsqueda de novedad y dificultades para recibir gratificaciones demoradas. Se ha relacionado con experiencias familiares, factores genéticos y disfunciones en el mecanismo de neurotransmisión cerebral de serotonina como mediador de la inhibición de conducta (Plutchik y Van
Praag, 1989). Un sujeto extravertido tiene conductas próximas a uno impulsivo, aunque con otro matiz. Se entiende por impulsividad la tendencia a responder rápidamente a los estímulos, sin reflexión y cometiendo por ello un alto porcentaje de errores en la respuesta (Schweizer, 2002).

Heaven (1993) asocia, entre otras, las dimensiones de Eysenck junto con una medida independiente de impulsividad en adolescentes. La impulsividad correlacionó significativamente con la delincuencia autoinformada en ambos sexos, mostrando un efecto directo en los varones y un efecto mediado por el psicoticismo en las mujeres. Tanto el psicoticismo como la sociabilidad, se relacionaron directamente con la conducta delictiva tanto en chicas como en chicos. La impulsividad en este caso se relacionó en los varones indirectamente a través del psicoticismo, y no hubo ninguna relación en el caso de las mujeres. La impulsividad, como rasgo de personalidad implicado en el neuroticismo y/o la conciencia mostraron asociaciones significativas con una escala que recogía elementos afectivos de placer-displacer (felicidad/infelicidad; alegría/fastidio; amistosidad/cólera; calma-intranquilidad; popularidad-soledad) y elementos de arousabilidad (alerta-somnolencia; fuerza-debilidad; excitación-aburrimiento; lleno de energía-cansado).

Los resultados obtenidos, en otro estudio, mostraron que la emoción es un componente importante de la impulsividad, la alta impulsividad correlacionó con un alto nivel de afecto negativo y baja arousabilidad tanto como con una mayor variabilidad afectiva y de arousal. Los niños impulsivos experimentaron más emociones negativas y sus estados emocionales fluctuaban más a lo largo de las dos semanas en las que se evaluó. Asimismo, cabría añadir que la impulsividad predijo el humor en los niños pero no en niñas.

Loeber, Stouthamer-Loeber, Van Kammen y Farrington (1989), postularon que las bajas puntuaciones en agradabilidad y la conciencia, así como la conducta delictiva se relacionan con un fallo en la adecuación en el control de impulsos (ego-control). En este mismo estudio los chicos que presentaron puntuaciones altas en conciencia y apertura y realizaron mejor las ta- 
reas académicas consideradas, presentando en general mejor ejecución escolar.

La impulsividad parece que implica velocidad en la respuesta, alta emocionalidad y ausencia de reflexividad asociada con motivaciones primarias; todo ello naturalmente incrementa la probabilidad de aparición de conductas violentas. Por ello, la impulsividad ha sido señalada como uno de los factores explicativos más potentes de agresión (Patterson, 1992) y de otras variables análogas como hiperactividad, alcoholismo, suicidio y conducta adictiva (Plutchik y Van Praag, 1989; Huang et al., 2001). Todas ellas pertenecen a la constelación de la violencia y actúan como multiplicadores de la misma.

Un aspecto especial de la impulsividad es la incapacidad que el sujeto tiene para diferir la gratificación. Esta característica se encuentra fuertemente asociada a la conducta delictiva y violenta, desde los estudios de Erikson (1968) al poner de manifiesto que los niños que, verbalmente y con acciones, tomaban la decisión de gastar inmediatamente el dinero obtenido protagonizaban más acciones violentas y eran más quebrantadores de normas que aquellos que, por el contrario, eran capaces de acumularlo.

La impulsividad juega un papel importante en la estabilidad de los niños para inhibir la agresión durante las señales de castigo (Atkins, Osborne, Bennett Hess y Halperin, 2001), al tiempo que como conducta inhibidora de estrategias de solución de problemas, induce a cometer mayores errores y exagerar las atribuciones hostiles (Dodge y Coie, 1987).

Al lado de las características de la personalidad que se muestran como estimulantes de la agresión, existen dimensiones personales relacionadas con su inhibición. Entre ellas se ha destacado especialmente la autoestima, la empatía y la autoeficacia.

\section{Autoestima}

Este concepto se difunde con el psicoanálisis y es, en su última raíz, una aceptación consciente de los distintos aspectos del ego. Desde un punto de vista evolutivo, la autoestima se cons- tituye mediante la interiorización de la imagen de si mismo fraguada en el espejo que nos devuelven los otros y fundamentalmente aquellos que forman el entorno inmediato del grupo al que se pertenece. Entre 0-2 años se fragua la imagen corporal, de 2-5 se produce la concepción incipiente del yo y de 5-12 se nutre y consolida una idea de si mismo que hace una crisis en la adolescencia y que permanece a lo largo de la vida (Coopersmith, 1967). Una de las peores formas de frustración es la que el sujeto siente respecto a sus propios logros. Cuando la autoimagen es mala, la frustración más honda está servida. El resentimiento que produce el descontento consigo mismo es una de las fuentes primarias de la agresión. Hay autores que consideran que la sobrevaloración de si mismo puede provocar el mismo efecto fundamentalmente en la infancia media, ya que se producen percepciones narcisistas que dificultan una buena integración y el rechazo del grupo. Una serie de trabajos han encontrado una relación entre autoimagen negativa y elementos que, a su vez, promocionan la agresión: es el caso de la depresión (del Barrio et al., 1994), con el rendimiento académico (Bosacki, 2003) con la falta de vínculos familiares (Simoms et al., 2001), factores que suelen aparecer frecuente y positivamente correlacionados con agresividad.

La relación indirecta del autoconcepto con la agresión se encuentra también a través de las habilidades sociales. Los niños con un autoconcepto negativo presentan también pocas habilidades sociales (Alonso y Román, 2003) y éstas a su vez inducen al rechazo y a su vez la agresión.

Se han hallado relaciones significativas entre la baja autoestima y varias formas de conducta exteriorizada, pero también se han hallado relaciones entre una sobreestimación de la competencia y la conducta agresiva al menos durante la infancia media (Edens, 1999).

Graziano, Jensen-Campbell y Finch (1997), con un conjunto de escalas de autoestima referidas cada una de ellas a distintos dominios concretos (académico, social atlético, aspecto físico y conducta), obtuvieron relaciones directas y significativas entre la autoestima social y las relaciones con los iguales de ambos sexos y entre la autoestima académica y todos los dominios 
de ajuste evaluados (ajuste académico, relaciones con los iguales, conducta en clase y relaciones con el profesor).

Otros datos interesantes al respecto aluden a que los niños rechazados-agresivos tienden a sobreestimar sus niveles de aceptación y popularidad entre sus compañeros de clase (Bukowski, Sippola, Verlan y Newcomb, 1993; Cillessen et al , 1992) y que los profesores evalúan a los niños agresivos-rechazados, significativamente menos competentes social y conductualmente que otros niños (Volling, MacKinnon-Lewis, Rabiner y Baradaran, 1993).

En general, los niños agresivos son evaluados como niños significativamente menos aceptados, menos competentes y más desviados en relación con problemas de conducta que los niños no agresivos.

Según Moore y Kikham (2001), los niños victimas de agresión en la escuela tienen una autoestima inferior a los que no son agredidos, por tanto la autoestima es un protector contra la agresión del otro.

\section{Autoeficacia}

La autoeficacia es aquella característica personal mediante la cual el sujeto se percibe como capaz de llevar a cabo sus propósitos. Se diferencia de la autoestima porque no se refiere al concepto de sí, sino a la capacidad de resolución de problemas. Bandura ha estudiado detenidamente la autoeficacia y su repercusión en la vida emocional, cosa que mucho antes había señalado Erickson, quien vio también la relación entre la autoeficacia y la agresión. Continuamente la frustración se relaciona con la agresión como ya hemos dicho; por tanto, si un sujeto es eficaz, su habilidad en la consecución de metas le mantendrá a salvo de situaciones frustrantes. Una correlación negativa entre agresión y autoeficacia aparece consistentemente en todos los estudios. Estos evidencian que los niños autoeficaces rinden más en la escuela, son más populares con los amigos y presentan una mejor adaptación social (Bandura, et al., 2001); exactamente lo mismo se ha encontrado en niños españoles, en donde la autoeficacia y el rendimiento correlacionan positivamente entre si y ambos ne- gativamente con agresión (Carrasco y del Barrio, 2002; Carrasco y del Barrio, 2003).

Los niños con un alto sentido de eficacia para los recursos agresivos, manifiestan metas hostiles ante situaciones de represalia, mientras que aquellos que presentan una alta eficacia percibida para los recursos prosociales, persiguen metas amistosas encaminadas a la resolución de problemas interpersonales (Perry, Perry y Rasmussen,1986), muestran que la percepción de eficacia, actúa como un mediador sociocognitivo en relación con los estilos de conducta agresiva o prosocial. Los sujetos que se perciben ineficaces en las actividades académicas, las relaciones interpersonales y en su capacidad para resistirse a la implicación en actividades de riesgo, presentan menores niveles de conducta prosocial y mayores niveles de síntomas depresivos como hemos visto anteriormente (Bandura et al., 1996).

Igualmente Allen, Leadbeater y Aber (1990), observaron que los sujetos con baja eficacia percibida de autocontrol, se implican más en actividades de consumo de drogas, conductas sexuales de riesgo y conductas delictivas.

Otros autores como Hoeltje, Zubrick, Silburn y Garton (1996) han estudiado la relación de la autoeficacia percibida en adolescentes con diversas medidas de funcionamiento familiar, como estilo educativo parental, uso de reforzadores, disfunción familiar y en relación con medidas de ajuste, como problemas interpersonales, consecución académica y puntuaciones en el cuestionario de psicopatología infantil de Achenbach en sus tres respectivas versiones autoinformada, padres y profesores (CBCL: Child Behavior Checklist; Achenbach; 1991a; 1991b; 1991c). De sus resultados concluyen que los sujetos con puntuaciones altas en autoeficacia tienen una actitud más positiva ante cualquier problema relacionado con estas variables.

\section{Empatía}

La empatía consiste en la capacidad de entender los sentimientos del otro lo que conlleva conductas de ayuda. Se considera que es una de las bases de la comunicación interpersonal y un instrumento potente para la inhibición de la 
agresión. Asimismo, se define como una respuesta afectiva para la aprehensión y comprensión del estado emocional del otro (Eisenberg et al., 1996). En ciertos autores, además de la aprensión cognitiva y afectiva se subraya la faceta de sentir la necesidad de ayudar al que lo necesita. La empatía es la base de la conducta altruista, que resulta incompatible con la agresión al otro, justo lo que se considera una conducta prosocial, diametralmente opuesta a la agresión y la violencia, de manera que, constantemente se ha estado encontrando una relación negativa entre empatía y agresividad. (Bandura et al, 1996; Mestre et al., 2000; Del Barrio, et al., 2003). Como han mostrado todos los estudios que se han realizado sobre el tema en muy diversas culturas.

Concretamente, en población española se ha encontrado repetidamente estos mismos datos que confirman el papel inhibidor de la empatía sobre la agresión (Carrasco y del Barrio, 2003).

La empatía en su doble dimensión cognitiva: percepción correcta de emociones, adopción de perspectivas) y afectiva (respuesta emocional congruente) mitiga e inhibe la agresión (Eisenberg, 1996).

Muchos autores señalan que una de las razones por las que las chicas son menos agresivas que los chicos se debe a sus altos niveles de empatía (Worthen, 2000) y las consecuencias que ello tiene en la capacidad de hacer amigos y pertenecer a grupos, lo que a su vez genera bajos niveles de agresividad.

\section{Factores sociales}

Los elementos sociales pueden pertenecer al microcosmos familiar o bien al mesocosmos o exocosmos que consideraremos a continuación.

\section{Factores Familiares}

Lo social tiene un ámbito muy vasto e interactivo pero no cabe la menor duda de que la familia es el primer ámbito de la socialización infantil.
El sujeto, por su inmadurez biológica, se nutre dilatada e inmediatamente de los estímulos que encuentra en el seno familiar, pero éste, a su vez, elabora sus normas y obtiene sus recursos de la sociedad y cultura que la alberga y la condiciona (Wahler, 1996).

La familia es la trasmisora de las normas básicas de las conductas que resultan adecuadas para instalarse en el mundo eficazmente. El niño absorbe las normas familiares con una facilidad sorprendente, posibilitada por un potente vínculo sentimental y la inmediatez y precocidad del contacto que son los elementos básicos del aprendizaje en la niñez. Piénsese en el lenguaje, que consiste esencialmente en unas reglas de comunicación; el niño aprende aquel que usa su familia mediante aprendizaje vicario y en él se siente instalado básicamente a lo largo de toda la vida, a pesar de que aprenda otros lenguajes más tarde. Algo muy paralelo ocurre con el aprendizaje de cualquier norma.

La familia tiene una estructura y una función (del Barrio, 1998). La función es la socialización y la estructura suele ser la nuclear (padres e hijos), pero que puede tener muchas variaciones y, en los últimos tiempos, han proliferado muchas y diferentes, que pueden ser más o menos facilitadoras de su función.

La familia tiene tres funciones básicas: protección, alimentación y educación. Todas ellas se desarrollan en un proceso complejo que puede llevarse a cabo porque hay una vinculación sentimental y una necesidad de integrar al sujeto joven en un grupo social.

El "Apego" es un vínculo amoroso primario que se establece entre el niño y la persona que lo cuida en sus primeros años. Cualquier persona que cuide primariamente a un niño puede establecer esos lazos amorosos que se generan en el contacto precoz y continuado. El apego es el más eficaz vehículo de la socialización. Alguna vez lo hemos denominado "la autopista de la socialización" por la rapidez que imprime a dicho proceso. En el desarrollo moral y social siempre hay un primer estadio elemental y biológico de placer o displacer y un segundo, ya social, en el que el niño se mueve buscando contentar a las personas que quiere. Este es el gran "haber" de la familia: sus vínculos afectivos. El 
apego, bien establecido, produce seguridad y facilidad para aprender, puesto que la actividad exploratoria del niño aumenta y con ella la rápida absorción de los modelos socialmente adaptados (Zahn-Waller y Radke-Yarrow, 1990).

En un estudio sobre este tema (Constantino, 1996), se muestra que la mayor parte de los niños diagnosticados con conducta agresiva patológica muestran un apego inseguro, evaluado con el "Test de la Situación ante el Extraño" de Ainsworth; además todos ellos presentaban puntuaciones más altas en conducta exteriorizada en el CBCL (Achenbach y Edelbrock, 1983); por el contrario el grupo control, con las mismas características psicosociales, pero con apego seguro, presentaba unas puntuaciones en conducta agresiva y violenta significativamente más bajas.

Otro estudio longitudinal (Egeland et al., 1993) ha mostrado que un apego inseguro entre seis meses y tres años es un buen predictor de la agresividad escolar de esos niños a los nueve años, sobre todo si se combina con hostilidad materna. En esa misma dirección apuntan los datos de Simons et al., (2001), que muestran cómo el apego está mediando en el desarrollo de características, tales como la cognición social y la autoestima, al tiempo que también lo hace con la agresión; de tal forma que los adolescentes con baja calidad de apego tienen también bajos niveles de cognición social, autoestima y alta conducta agresiva.

En la familia son especialmente importantes los tipos de crianza que canalizan la socialización del niño.

Así como el apego tiene su vigencia máxima en los tres primeros años de vida, la vigencia de la crianza dura hasta la adolescencia. La crianza y los modelos educativos parentales, están unidos a un padre/madre/ hijo que potencia, fomenta, o promueve todos los aspectos del crecimiento del niño, conduciendo y guiando la nueva vida a través del desarrollo personal, social y emocional. Dada la incidencia en los problemas conductuales/y o emocionales del hijo, resulta particularmente relevante conocer los modelos educativos que utilizan los padres que pueden incidir en estos problemas.

Se han establecido tres grandes géneros: Permisivo, Autoritario y Autorizado. En el estilo per- misivo se incluyen, por orden creciente el laissezfaire, la hiperindulgencia, el desafecto, el descuido y el abandono. En el Autoritario, se encuentra el perfeccionismo, la rigidez, la dureza, el rechazo y el maltrato. Por último, el modelo Autorizado se caracteriza por la atención, dedicación, afectuosidad, control, flexibilidad y disciplina.

Los niños sin problemas suelen tener este último tipo de crianza, siendo la negociación una de las conductas características en este tipo de familias (Schaffer, 1989).

La calidad de las relaciones de crianza correlaciona positivamente con nivel de adaptación de los hijos, popularidad, competencia académica y calidad del grupo de amigos, y siempre negativamente con la agresión, como muestran algunos estudios longitudinales (Xie et al., 2001). Naturalmente, en el reverso de la moneda encontramos que las malas relaciones con los hijos y el abuso, en cualquiera de sus formas, resulta ser un factor de riesgo importantísimo de la violencia en los jóvenes (Sanmartín, 1999). Todo ello se complica aún más si el sexo es masculino y la clase social baja.

En población española hemos encontrado datos que apoyan estas tesis: los padres con una crianza que da apoyo, controla la conducta de sus hijos y es flexible en las normas, produce efectos beneficiosos sobre cualquier tipo de emociones, ira y agresividad incluidas (Roa y del Barrio, 2002; Del Barrio y Aluja, 2004; Tur et al., 2004).

Entre todas las posibles combinaciones, aquella que une el desafecto y la ausencia de normas es la que produce consecuencias más desastrosas en el proceso de socialización, puesto que se contravienen las bases más profundas de la misma: la pertenencia a grupo y la asunción de sus normas. En este tipo de estudios se ha encontrado también que las madres que tienen una alta desiderabilidad social provocan un aumento de la conflictividad en los hijos (Roa y del Barrio, 2003). Probablemente a la base de este fenómeno se encuentra un desajuste entre expectativas y logros que siempre son fuente de frustración y, por tanto, de la probabilidad de aparición de la agresión.

Además de esa socialización sentimental, a la que venimos haciendo referencia, se da el 
aprendizaje social (Bandura, 1982). Los padres primero, los compañeros y los "ídolos" sociales más tarde, proporcionan los modelos que se copian. El aprendizaje vicario tiene su época más activa entre los 0-4 años y tanto unos modelos como otros obtienen su influencia y su fuerza del cariño o la admiración, que son a su vez realidades emocionales.

Otros elementos familiares son también de gran relevancia. Ya, en el estudio llevado a cabo hace años por Thomas et al., (1968), se aislaron unos elementos ambientales perturbadores que, esencialmente, se conservan y que hacen referencia a la interacción entre aspectos personales y sociales. Para Baumrind (1967), tanto aquellos padres que utilizan modelos educativos basados en el autoritarismo, como los que utilizan métodos permisivos o indulgentes con sus hijos, tienden, con frecuencia, a tener hijos con comportamientos de tipo agresivo, con escasa autoestima y alta impulsividad. Particularmente, las conductas de hostilidad y agresividad que se dan en niños educados con un modelo autoritario, se deberían al exceso de castigo y al uso frecuente de técnicas de poder (Baumrind, 1967). Parece ser que las relaciones conflictivas padres-hijo que suelen darse en el modelo autoritario, son las que producen niveles más elevados de conducta agresiva en el niño (Sanders et al., 1992). Para otros autores, todas las características del modelo autoritario, tomadas globalmente, se señalan como factores de riesgo para el desarrollo de la conducta agresiva y hostil del niño (Meeters et al., 1994). Sin embargo, no falta quien considera que la hostilidad y la agresión se deben fundamentalmente al escaso o nulo apoyo afectivo que los padres expresan a sus hijos y niveles bajos de compromiso en la educación (Maccoby y Martín, 1983).

Bronfenbrenner (1979), desde una postura ecológica, propone la existencia de cuatro niveles de sistemas ambientales diferenciados que son la base del desarrollo humano: el microsistema, el mesosistema, macrosistema y exosistema, todos ellos interactúan entre si, pero afectan al sujeto con una menor o mayor proximidad. Basándose en la metáfora de la familia como "ecosistema", dicho autor, analiza las interrelaciones que se producen entre los miembros de la familia y su entorno social y cultural. Así los sistemas educativos de los padres, van a estar relacionados con el apoyo que los padres reciben tanto de la familia como de los amigos, o de cualquier tipo de institución social. La pertenencia a una determinada clase social está asimismo unida al nivel educativo que, a su vez, está relacionado con el estatus de trabajo parental y con las normas y valores desarrollados por las distintas clases sociales. En los últimos años, se achaca a la televisión el aumento de la agresividad y violencia del niño; sin embargo, también cabría pensar que lo que realmente hace este medio, es impedir la comunicación, los juegos y las discusiones entre padres-hijos, a través de las cuales se produce gran parte de la educación del niño (Bronfenbrenner, 1974a) .

En la misma línea Belsky (1984), considera que la educación del niño está determinada por las características de éste, la de los padres y la del contexto en el que se mueven.

En el análisis de los elementos familiares adquieren relevancia algunas características paternas especialmente peligrosas en relación con la aparición de agresión en el hijo. Como no podía ser menos, dado que el aprendizaje vicario es fundamental en el niño, la violencia paterna es un gran factor de riesgo. Padres agresivos suelen tener hijos con esta misma conducta (Goetting, 1994). En estudios observacionales se aprecia, como el padre agresivo es poco afectuoso con sus hijos (Burgental, Love, Kaswan y April, 1975) y suele ser también una persona desadaptada, incoherente, arbitraria y dada a las explosiones de cólera. Este tipo de conducta parece ser parte de un sistema familiar conflictivo donde los hijos están expuestos constantemente a situaciones de violencia (Patterson, 1976). Por tanto, hijos con conducta antisocial, suelen tener padres con este mismo problema (Phares, 1996). A esto se añade el problema del alcoholismo paterno que, por otra parte, es probable que promuevan conductas antisociales, tales como agresividad y malos tratos (West y Prinz, 1987).

En el caso de la madre, las conductas emocionalmente negativas representan el mayor factor de riesgo. Las madres depresivas perciben mayor número de problemas de conductas, tanto interiorizadas como exteriorizadas, en sus hi- 
jos (Roa y del Barrio, 2003) lo que aumenta la crítica y la mala relación. Tallegen (1985) mantiene que la madre neurótica promueve experiencias emocionales que son negativas para su hijo. Para Belsky et al., (1995) las madres con niveles altos de neuroticismo se caracterizan por un modelo educativo carente de afecto y sensibilidad hacia el hijo. Se puede decir que el neuroticismo materno predice ciertas características negativas en la conducta del niño.

Por el contrario, la extroversión materna actúa como un antídoto (Belsky, et al., 1995). Los estudios sobre este aspecto indican que las madres con puntuaciones altas en extraversión, medida a través del (NEO-PI; MacCrae y Costa, 1984) son más afectuosas, sensibles y cariñosas. En cualquier caso, la extraversión materna está unida a experiencias positivas (Tellegen, 1985). En este sentido, podría interpretarse que la extroversión materna esta considerada como un factor inhibidor de problemas en el niño. Concretamente en población española se ha encontrado una relación negativa entre extroversión materna y agresión (Roa y del Barrio, 2002).

Otro de los elementos familiares relacionados con la agresión infantil son las relaciones matrimoniales. Para algunos autores estas relaciones son consideradas como el centro o el corazón de la solidaridad y, por tanto, el elemento esencial que determina la calidad de la vida familiar (Steger y Kotler, 1979). Se asume que las relaciones matrimoniales afectan a la vida familiar a través de las interacciones que se establecen entre los padres y los hijos (Erel y Burman, 1995). Según los estudios realizados el desajuste matrimonial está relacionado con problemas de conducta exteriorizada en los hijos. Los niños con padres que tienen este tipo de problema presentan más agresividad, delincuencia (Egeland et al., 1988) y hostilidad (Kering, 1995). Este tipo de conducta aumenta con la edad, por lo que es más fácil encontrarlos en los adolescentes (Jouriles et al., 1991).

El fracaso escolar se da con más frecuencia en este tipo de familias, con lo que se acumulan dos factores de riesgo agravándose el problema en el caso de los varones (King et al., 1995). La respuesta del niño a las desavenencias matrimoniales se modula en función del sexo. Los chicos reaccionan de forma más violenta que las chicas. La explicación posible es que los chicos son más vulnerables biológicamente a un amplio rango de situaciones psicosociales (Eme, 1979). No obstante, otra explicación puede ser que los padres castigan con más frecuencia a los chicos que a las chicas (Hetherington, Cox y Cox, 1982).

Los padres con desavenencias están menos comprometidos en la crianza y utilizan con mayor frecuencia técnicas educativas basadas en la imposición y el uso frecuente del castigo (Kitzmann, 1999). Parece que los problemas del niño, en familias conflictivas, derivarían de los límites poco claros y las expectativas inadecuadas que estos padres, enfrascados en sus conflictos, tienen de sus hijos (Patterson, 1982).

A pesar de que el divorcio puede ser una solución positiva al destructivo funcionamiento familiar, sin embargo, para los hijos, el periodo de transición que sigue a la separación o divorcio es estresante. Durante el primer año, los niños de cualquier edad suelen tienden a sentirse depresivos, infelices ansiosos y socialmente aislados. En niños de corta edad, se da con frecuencia un aumento de las conductas de queja, agresividad y negativismo, independientemente del sexo (Hetherintong, Cox y Cox, 1982).

La revisión de 92 estudios, sobre este tema, realizada por Amato y Keith (1991a) indican que los efectos del divorcio en el niño incluyen áreas como rendimiento escolar y problemas de conducta. Existen diferencias de sexo en la forma de reaccionar ante la situación estresante del divorcio. Los chicos presentan conductas de aislamiento social, se sienten más tristes y desdichados y con una autoestima muy baja (Kurder, 1988), con un aumento de la conducta antisocial (agresión, ira y hostilidad) en los adolescentes (Hetherington, Cox y Cox, 1977b) y un bajo rendimiento escolar (Allison y Furstenberg, 1989). Como siempre, en las chicas el nivel de agresividad y el descenso de rendimiento escolar es menos acusado (Rutter, 1983), aunque las alteraciones emocionales son mayores (Hetherington, Cox y Cox ,1978). Aunque el divorcio conlleva un factor de riesgo de aparición de agresión, algunas variables pueden modular sus efectos: la edad del niño, el sexo y estatus socioeconómico. Asimismo una buena relación con el padre que detenta la custodia puede amortiguar 
el efecto que produce el divorcio (Wierson et al., 1989).

Dentro de las distintas formas de estructura familiar, la que mayor relación guarda con la agresión, es el hogar monoparental. La mayor parte de las veces esta situación se produce por abandono o por divorcio, y el hogar suele estar al cargo de la mujer. Por lo general, las madres que viven solas tienen un exceso de trabajo, que deriva de ser cabeza de familia. Los horarios de trabajo suelen ser muy dilatados o extensos con lo que suele darse una ausencia de supervisión o control de los hijos (Hetherington, et al., 1993), que hace que la madre tenga problemas con la autoridad y la disciplina que, a su vez, va a tener repercusiones negativas para el niño. Los cuidados y atención prestados a sus hijos suelen ser muy bajos; su conducta es más hostil y más restrictiva, la comunicación y sensibilidad hacia el niño es menor que la que se da en otras madres que no se encuentran en estas circunstancias (Howes y Stewart, 1987). Como concluye Demo (1988), a la hora de imponer disciplina y supervisar la conducta del hijo, estas madres suelen tener problemas. Otras conductas infantiles que acrecentan su probabilidad, en familias compuestas monoparentales son la hiperactividad, aislamiento social y bajo rendimiento académico. Al llegar a la adolescencia existe la posibilidad de caer en la marginación, al implicarse en grupos donde el consumo de droga, la violencia y el vandalismo son la tónica general, siendo los chicos los que tienen mayor probabilidad de riesgo en comparación con las chicas (Hetherington y Parke, 1993).

Las condiciones en las que viven los hijos de padre único se pueden ver paliadas por el apoyo de amigos o familiares que actúan como factores moduladores. Las madres pueden encontrar apoyo material o psicológico que va a repercutir en su autoestima, del mismo modo, el niño se beneficia de las relaciones con otros familiares. La presencia de otros adultos en el hogar facilita la supervisión y el control de la conducta del niño y del adolescente, reduciendo el índice de problemas (Dornbusch et al., 1987).

En líneas generales, se supone que el divorcio, el abandono o la viudedad, no producen directamente efectos negativos en los niños, pero sí las circunstancias que suelen acompañarlos: malas relaciones entre los padres, descenso económico, la falta de tiempo y la sobrecarga laboral. En estos casos, los recursos y la capacidad de supervisión descienden y con ello aparecen, la indisciplina y los problemas de conducta, resintiéndose también el rendimiento escolar. Todo ello son factores que inciden en el hecho de que las tasas de agresión sean más elevadas en este tipo de familias (Pons y del Barrio, 1995).

\section{La Escuela}

Además de la familia, en el microcosmos del niño se encuentra otro importante factor: la escuela. No solo los padres socializan a sus hijos, los maestros y los iguales son otro medio a través del cual los niños pueden adquirir conductas socialmente aceptables o inaceptables. Existe evidencia de que los niños con altos índices de agresividad son vistos por sus profesores como niños difíciles (Cillessen et al., 1992; Bukowski, Sippola, Verlan y Newcomb, 1993) El fracaso escolar suele ser una de las notas dominantes. Los niños agresivos son evitados por sus compañeros, lo que les lleva al aislamiento social, a la frustración y a la búsqueda de compañeros rechazados por las mismas razones.

Normalmente, son estos niños rechazados y constituidos en grupos, los que atacan y maltratan a otros compañeros en la escuela, fenómeno al que hemos hecho referencia anteriormente (bullying). Según datos de la fundación Santamaría (Valencia, Investigación sobre niños escolarizados), el 30\% de los niños abandonan sus estudios y el $84 \%$ de los niños detenidos por delitos con violencia presentan fracaso escolar.

Todos los niños que han tiroteado a sus compañeros en la escuela y que han sido estudiados en USA tienen como denominador común el fracaso escolar y el no tener amigos.

\section{Clase social}

La sociedad proporciona a sus miembros un conjunto de recursos y un sistema de valores que condicionan muchas de las conductas de 
sus miembros y éstas varían en función de las distintas clases sociales.

Entre los recursos relacionados con la violencia hay que plantearse la carencia de ellos, es decir, el tema de la pobreza. En líneas generales, las clases sociales deprimidas acumulan factores de riesgo que hacen que se produzca un incremento de las conductas violentas y agresivas, las razones para ello son plurales y vamos a considerar algunas de ellas.

En primer lugar, el nivel de educación es más bajo, con lo cual los recursos de autocontrol son menores y los sujetos con poca educación no tienen acceso a una profesión segura desde un punto de vista económico. Por tanto, la frustración es más alta, al igual que la tentación de tomar por la fuerza lo que no se puede conseguir de otro modo.

En un reciente trabajo Evans (2004) demuestra cómo los bajos ingresos correlacionan con un cúmulo de carencias de otro orden entre las que hay que mencionar las siguientes: menos control de tareas escolares, más horas de televisión, menos acceso a libros y computadores, más familias rotas o desestructuradas, más violencia en el hogar, menos responsabilidad paterna y más autoritarismo, menos seguridad policial en los barrios, peores escuelas, menos recursos de ocio controlado, entornos más ruidosos y polucionados y peor salud. A todo ello, se une el tamaño de la familia que, en el caso de encontrarse incrementada, aumenta los problemas de control de la conducta de sus miembros jóvenes, todo ello unido a la escasez de recursos, lo cual es todavía más grave cuando la madre, que está al cargo de estas familias es muy joven, circunstancia, por lo demás, muy frecuente en estos casos (Rutter, 1998). Por añadidura en la clase social baja es más fácil que se produzca el desempleo, con la agravación de los problemas económicos pertinentes y la aparición de las desavenencias matrimoniales frecuentemente aireadas (Bronfenbrenner, 1958).

Los padres de clase social baja utilizan con frecuencia, en la educación de sus hijos, el castigo y las prohibiciones. Como consecuencia de las condiciones negativas en las que se desenvuelve su vida, los niños tienen más problemas emocionales y conductuales (Conger et al.,
1993). La mayoría de las investigaciones realizadas en este ámbito coinciden en que la agresividad y la violencia es superior en niveles económicos bajos, en los que existe mayor desempleo y menor nivel de estudios; igualmente en los estudios sobre victimización aparece reiteradamente un dato: las familias procedentes de contextos deficitarios agreden más a sus hijos y parejas.

Como ha señalado McLoyd (1991), en una extensa revisión sobre las desventajas socioeconómicas y el desarrollo infantil, las situaciones de pobreza predicen dificultades cognitivas, bajo nivel intelectual, bajos niveles de logro académico y un incremento de los niveles de problemas socioemocionales. El nivel socioeconómico condiciona variables tales como el logro escolar, las interacciones verbales entre padres e hijos, las expectativas de los padres sobre el éxito de sus hijos, el estado de salud, las actitudes de los profesores, las relaciones afectivas positivas, los eventos estresantes vividos, así como las estrategias de disciplina y control, todos ellos elementos mediadores que ejercen importantes efectos sobre el óptimo desarrollo del niño.

En aquellos estamentos de la población con peores condiciones económicas la prevalencia de problemas de conducta ha sido superior en relación con otros niveles económicamente más favorables (McLoyd,1991; Conger, Conger, Elder, Lorenz, Simons y Whitbeck, 1993). Estos autores han destacado tanto problemas externalizados (agresividad, impulsividad, hiperactividad...) como internalizados (ansiedad, depresión...) con un predominio de los primeros en las clases sociales más desfavorecidas (McLoyd, 1991; McLoyd, Jayaratne, Ceballo y Bohórquez, 1994) entendiendo que esta situación actúa como factor de riesgo al desarrollo de conductas delincuentes.

Otros factores mediadores que pueden explicar el aumento de alteraciones emocionales infantiles en las clases sociales bajas, han sido enunciados por McLoyd (1998), destacando los problemas de salud mental de los padres, los conflictos entre cada uno de los padres y el número de eventos vitales negativos vividos, los cuales contribuyen a que éstos exhiban menores conductas positivas en la interacción con sus hijos (Conger, et al., 1993). Asimismo, el au- 
mento de prácticas disciplinarias inadecuadas (coercitivas, inconsistentes, hostiles, dominantes...), la exposición a modelos adultos agresivos, la falta de calor materno, valores agresivos familiares, falta de apoyo social y falta de estimulación cognitiva, son factores que favorecen las dificultades emocionales (Dodge, Pettit y Bates, 1994).

Considerado todo ello en conjunto, no es raro que el bajo nivel económico tenga una correlación con la agresión (Dodge, Petit y Bates, 1994; Guerra, Huessmann, Tolan y Acker, 1995).

Hay que señalar, no obstante, que los estudios realizados por Olweus (1984) no encontraron relación entre el estatus socioeconómico de las familias y el nivel de agresividad de los chicos. Parece que más que la pobreza en sí misma, son los factores que están asociados con ésta los que incrementan el riesgo para la agresión (Dodge et al., 1994; Guerra et al., 1995).

\section{Factores contextuales}

No solo las variables personales y familiares influyen en la conducta, también es importante el influjo que ejercen las situaciones donde los individuos se desenvuelven y realizan su vida social. Analizaremos en este epígrafe los factores contextuales relacionados con la agresividad: el barrio en el que se habita y el contenido de la TV.

\section{El Barrio}

Los barrios pobres o marginales concentran una gran cantidad de personas que carecen de recursos económicos, con alta densidad de desempleo y con gran porcentaje de familias monoparentales, este hecho puede influir en la conducta agresiva del niño. Otro aspecto a tener en cuenta es que, en el barrio, la conducta agresiva del niño puede verse como un atributo muy apreciado.

El efecto que produce en los hijos vivir en barrios marginales, considerados de alto riesgo sobre todo en las grandes ciudades, ha sido estudiado por diversos autores (Rutter et al., 1979), quienes concluyen que dichos niños tienen mayores tasas de desórdenes conductuales y emocionales que los que no están en esta circunstancia (agresividad, bajo nivel cultural, desordenes mentales o criminalidad).

El pandillismo, que se asocia fuertemente a la agresión juvenil, se ve potenciado por el mayor o menor acceso a estos grupos que ofrecen los distintos barrios. Un dato al respecto: el 54\% de la agresividad en jóvenes se produce en el seno de una banda.

\section{Televisión}

Algunos programas de televisión que incitan a la violencia pueden ser causa de un aumento de agresividad en el niño.

No es raro, hoy día, que los niños dispongan de televisión en su propia habitación. Los padres, a veces, son muy permisivos y dejan que los hijos la manejen a su antojo, sin saber, en la mayoría de los casos, los programas que sus hijos están viendo. Esto se incrementa cuando los niños tienen TV en el dormitorio. Según las encuestas, en España, el 33\% de los niños tienen televisor propio y pasan más horas ante él que en la escuela.

A esto hay que añadir el problema del aprendizaje vicario, el $96 \%$ de los programas televisivos incluyen temas más o menos violentos, sólo el 4\% son antiviolentos (Donnerstein, 2003).

Los trabajos de Eron (1963) son pioneros y especialmente interesantes por ser sus datos el resultado de un estudio longitudinal. Se sostiene (Eron et al. 1973) que los niños que ven programas violentos, y gustan de ellos, en la primera infancia son mayoría, pero la influencia de esta afición en su agresividad en la vida real, así como su interés por la violencia televisiva en el futuro depende de si el niño era o no agresivo en la infancia. Los que lo eran mantienen el gusto en etapas posteriores, los que no lo eran no mantienen esa afición; por otra parte, los niños agresivos con gusto por la TV agresiva en la infancia son también más agresivos en edad adulta.

Para explicar la acción de la TV sobre la aparición de la agresión se recurre a varias teorías: en las cuales de destaca la "Identificación" (aprendizaje vicario), la "Desensibilización" (que 
inhibe una respuesta de desagrado innata hacia la agresión) y una "Tercera variable", referida a las condiciones personales, temporales, familiares y ambientales donde el niño ve la TV.

Un trabajo reciente sobre este tema (Huesmann et al., 2003) muestra que los niños que ven TV violenta tienen una conducta más violenta 15 años más tarde. Este fenómeno afecta más a los hombres que a las mujeres. Por otra parte, se ha de tener en cuenta también el grado de identificación que se produce con los personajes violentos y la percepción de realismo de la ficción. Los individuos más jóvenes se ven más afectados que los adolescentes o adultos. En esta misma dirección apuntan los trabajos de Meyers (2003). Además, la agresión futura correlaciona más fuertemente en aquellos sujetos que previamente tenían altos niveles de agresión, tanto autoinformada como heteroinformada; lo mismo que aparecía ya en los trabajos de Eron, citados con anterioridad. Además, la educación paterna y el éxito escolar son las variables que correlacionan negativamente con más potencia, con ver TV violenta y con agresión tanto en niñas como en niños.

Otro efecto indeseable de la violencia televisiva es que los sujetos no agresivos incrementan su miedo a ser víctimas y este miedo les convierte en dianas de la agresión de sus compañeros agresivos.

Es evidente que la violencia de los medios de comunicación no es algo positivo, pero tampoco se puede decir que sea la "causa de la violencia" sin más, aunque sí un instigador de las formas de la misma.

Por si fuera poca la influencia de la televisión, recientemente se han añadido los videojuegos. La mayoría de los estudios presentan problemas metodológicos y sólo obtienen medidas de la agresión a corto plazo. A pesar de esto, la mayoría de los resultados coinciden en mostrar que los niños se muestran más agresivos después de ver o jugar con un videojuego violento (Funk, Hagan, Shimming, Bullock, Buchman y Myers, 2002).

Hay razones para pensar que los videojuegos tienen un mayor efecto sobre la conducta violenta que las películas, posiblemente por las características de realidad virtual que presentan.
La preferencia por juegos electrónicos violentos parece asociarse con mayores problemas de conducta global y conductas interiorizada (problemas de pensamiento y ansiedad, depresión) pero no en conductas externalizantes incluidas la agresión. Según Funk, Hagan, Shimming, Bullock, Buchman y Myers (2002), los niños con preferencia de juegos violentos puntúan más en todas estas variables que los que no tenían esta preferencia. La explicación puede encontrarse en un modelo de desensibilización, por el que la exposición a la violencia hace que la percepción de la conducta propia de un niño, no sea percibida como agresiva. Por otra parte, esta exposición puede promover una desconexión entre las emociones normalmente asociadas con los actos violentos (contracondicionamiento o desensibilización).

Atendiendo a las consecuencias de los videos juego, Anderson y Bushman (2002) han propuesto el General Agression Model (GAM) que consiste en diferenciar los elementos que intervienen en el proceso del aprendizaje de la violencia. Bajo este modelo se distingue, en primer lugar, las variables de personalidad (actitudes a la violencia, rasgos de hostilidad) y variables situacionales (exposición a la violencia real o multimedia) que interactúan para influir en el estado interno de los individuos: cogniciones (guiones agresivos, pensamientos hostiles), afectos (sentimientos de hostilidad, ira) y arousal (tasa cardiaca, presión sanguínea) de manera que todos ellos interactúan para producir la interpretación de los individuos de un acto agresivo y la activación de los consiguientes procesos de toma de decisiones. Los videojuegos tienen efectos a corto y largo plazo; a corto, como una variable situacional que resulta en un incremento en las cogniciones, afectos y arousal y, a largo plazo, influyen en la promoción de creencias agresivas y actitudes creándose esquemas agresivos, guiones conductuales agresivos y expectativas agresivas, tanto como la desensibilización a la agresión. Estos factores sesgan la personalidad del sujeto hacia la agresión, si bien hay pocos datos de los efectos de los videojuegos a largo plazo.

La relación entre videojuegos y agresión la explica Kirsh (2003) con los siguientes argumentos: 
1. Los adolescentes son más agresivos y por tanto se sienten más atraídos por actividades de agresión. Más tarde la agresión decrece y esta preferencia también.

2. Los sujetos con altos niveles de arousal se sienten más atraídos por imágenes violentas. Esto ha sido puesto de manifiesto en sujetos con alta tasa cardiaca, altos rasgos de búsqueda de sensaciones. En sujetos con alta hostilidad y elevados niveles de adrenalina los niveles de agresión son superiores y, por tanto, el video juego les refuerza sus experiencias.

El incremento de la agresión en la adolescencia temprana afecta al estado interno de las variables del GAM reforzando e incrementando las cogniciones afectos y arousal, reforzando y creando afectos hostiles e incrementando el arousal relacionado con la agresión. Los videojuegos pueden ser más pronunciados en la adolescencia temprana que en la media y tardía adolescencia. El elevado arousal fisiológico experienciado en los adolescentes tempranos interactúa con el estado interno de arousal causado por la violencia de los video-juegos para crear así un nivel acumulativo de excitación interna que es mayor que en la adolescencia media y tardía, resultando en más conducta agresiva. La toma de decisiones está en función del nivel de desarrollo: en la adolescencia temprana los individuos toman decisiones más impulsivas, con poca evaluación cognitiva durante las situaciones de carga emocional, en cambio, en la adolescencia tardía, la toma de decisiones llegará a ser más racional y evaluativa.

\section{Abuso de Sustancias}

Se sabe que el alcohol, es un buen predictor y un precipitante de la conducta violenta, principalmente en hombres. La comorbilidad entre abuso de drogas y psicopatología predice mejor la conducta violenta en las mujeres que en los hombres (Nagin,.\& Tremblay, 2001).

En cuanto al resto de drogas ilegales, podemos decir que predicen la conducta violenta tanto en hombres como en mujeres (Dodgen, \& Shea, 2000).
Recientemente, se ha hallado una relación entre el consumo de cocaina y descenso de la capacidad de concentración y el consiguiente descenso del rendimiento escolar. Otro dato interesante hace referencia a que, los brotes esquizofrénicos en adolescentes se consideran precipitados por la ingestión de drogas (Dodgen, \& Shea., 2000)

La relación de la droga con otras emociones relacionadas con la agresividad, como es la culpa, la envidia, la vergüenza y los celos, han sido escasamente estudiadas; aunque la vergüenza y la culpa, como emociones sociomorales, se han asociado más directamente con la agresividad (especialmente la culpa se ha mostrado como un inhibidor de la conducta antisocial, el consumo de drogas y la conducta agresiva).

El incremento del consumo de sustancias psicoactivas en jóvenes, así como la tendencia a llevar a cabo esta conducta de forma precoz, tiene que alertar no sólo en relación con la salud, sino también con la posibilidad de un incremento mayor de la agresión.

\section{Factores de protección}

Considerados en su conjunto, los elementos sociopersonales relacionados con el incremento de la agresión y la violencia en los individuos jóvenes nos dan las pistas tanto de los factores que permitan la posibilidad de prevención de la misma, como de aquellos que resultan escudos protectores contra su aparición.

Como las condiciones naturales no son cambiables, tendremos que centrar los esfuerzos en los elementos educativos que pueden llegar a producir, mediante el hábito, modificaciones incluso en estructuras que antes eran consideradas como inmutables.

En primer lugar, se advierte que hay que incrementar la convivencia entre padres y niños pequeños para que la formación de fuertes lazos afectivos se refuerce y que ello haga posible la trasmisión de valores de socialización en la primera etapa de la vida que es, por otra parte, la más receptiva para la formación de hábitos que encaucen la tendencia egoísta en la que se forjan la mayor parte de las conductas agresivas. 
Por otra parte, hay emociones y actitudes que resultan incompatibles con la violencia. Entre ellas destacan: la empatía, la generosidad o la autoestima. Todas ellas son los grandes inhibidores de la agresión y eso se consigue sólo en una comunicación individualizada y cálida, es decir, en el seno de una familia.

Junto a esto, cada familia tiene que tener perfectamente claro que una relación afectuosa es el clima ideal, una cualidad que no tiene nada que ver con la permisividad. El mundo familiar debe ahornar la conducta de los niños, esto se lleva a cabo estableciendo unas normas de convivencia claras y el control de su cumplimiento.

Asimismo, deben ser instituidos hábitos de esfuerzo, nada de lo verdaderamente valioso es gratis. La educación de la persona es la tarea ineludible de los padres y no puede ser de ninguna manera delegada.

En segundo lugar, habría que considerar el apoyo social a las familias que acumulen factores de riesgo para que puedan optimizar los hábitos de crianza y evitar el conflicto familiar con la ayuda de expertos que actúen en los momentos concretos en el contexto familiar. Es evidente que retirar la patria potestad es una decisión drástica a la que sólo habría que llegar en casos extremos y que hay un camino intermedio que todavía está sin explorar y cuyo coste social debemos asumir cuanto antes.

En tercer lugar, todos los datos apuntan a que el fracaso escolar es un caldo de cultivo de la violencia. La detección precoz y prevención de los problemas de aprendizaje, la vigilancia de las tareas escolares por parte de los padres y el apoyo en las dificultades de integración de todo tipo es una meta imprescindible. La administración tiene el papel sobre todo de adecuar los sistemas de enseñanza, de tal modo, que se combata el fracaso escolar, no bajando el listón para todos, sino elevando el nivel de ejecución de los individuos que tienen dificultades escolares. El profesor tendrá éxito en esta labor, si trabaja con sujetos que son personas y que se forman como tales en el seno de la familia.

Por último, la sociedad debe tomar conciencia absoluta de que hay que tener una permisividad cero ante la violencia. Es la presión social y no las leyes las que deben actuar sobre los ni- ños. Los valores que se comunican a través de los ídolos, los modelos de ficción, las metas a conseguir, que son las que los niños absorben a través de los videojuegos, el cine y sobre todo la televisión, deben ser adecuadas al fomento de conductas no violentas.

Si queremos jóvenes esforzados, afables, competentes hay que transmitirles el esfuerzo, la afabilidad y la competencia, con ello conseguirán lo que deseen de la vida sin necesidad de agredir, pero para que estos fines sean posibles se requiere parafrasear la famosa sentencia " Cada sociedad tiene los jóvenes que se merece”.

\section{Referencias}

Achenbach, T. y Edelbrock, C.S.(1983). Manual for the Child Behavior Checklist and Revised Behavior Profile. Burlington: University of Vermont.

Achenbach, T.M.(1981a). Manual for the Child Behavior Checklist and 1991 profile. Burlington, V.T.: University of Vermont, Department of Psychiatry.

Achenbach, T.M. (1981b). Manual for the Younth Self.Report and 1991 profile. Burlington, V.T.: University of Vermont, Department of Psychiatry.

Achenbach, T. y Edelbrock, C.S.(1987). Manual for the Youth self report and profile. Burlington: Department of Psychiatry University of Vermont.

Akiskal, HS. y McKinney, WT. (1975). Depressive disorders: Toward a unified hypothesis. Science, 182, 20-28.

Alonso, J. y Román, J.M. (2003). Educación familiar y autoconcepto en los niños pequeños. Madrid: Pirámide.

Allison, P.D. y Furstenburg, F.F. (1989). How marital dissolution affects children: variations by age and sex. Development Psychology, 25, 540-549.

Allen, J., Leadbeater, B. y Aber, J. (1990). The relationship of adolescents expectations and values to delinquency, hard drug use, and unprotected sexual intercourse. Development and Psychopathology, 2, 85-98.

Allport, G. W. (1937). Personality: A psychological interpretation. New York: Holt. 
Amato, P.R. y Keith, B. (1991a). Parental divorce and the well-being of children: A meta-analysis. Psychological Bulletin, 110, 26-46.

Amato, P.R. y Keith, B. (1991b). Parental divorce and adult well-being: A meta-analysis. Journal of Marriage and the Family, 53,43-58.

Anderson, C. y Bustman, B. (2002). Human Agression. Annual Review of Psychology, 53, 27-51.

Atkins, M.S., Stoff, D.M., Osborne, M.L. y Brown, K. (1993). Distinguishing Instrumental and hostile aggression: does it make a difference. Journal of Abnormal Child Psychology, 21, 355-365.

Beck, A. (2003): Prisioneros del odio. Barcelona, Paidós.

Bandura, A. (1973). Aggression: A social learning analysis. New Jersey: Prentice-Hall, Englewood Cliffs.

Bandura, A., Barbarelli, C., Caprara, V. y Pastorelli, C. (1996). Mechanism of moral disengagement in the exercise of agency. Journal of Personality and Social Psychology, 2, 364-374.

Bandura, A. (1982): Teoría del aprendizaje social. Madrid: Espasa.

Bandura, A. (2001). Self-efficacy beliefs as shapers of children's aspirations and career trajectories. Child Development, 72, 187-206.

Baumrid, D. (1967). Child care practices anteceding three patterns of preschool behavior, Genetic Psychology, 4, 99-102

Baumrid, D. (1993). The Average Expectable enviroment is not good enough: a response to scar. Child Development, 64, 1299-1317.

Belsky, J., Steimberg, L. y Draper, P. (1991). Childhood experience, interpersonal development, and reproductive estrategy: an evolutionary theory of socialization. Child Development, 63, 647.670.

Belsky, J. (1984). The determinants of Parenting: A process model. Child Development, 55, 83-96.

Belsky, J., Crnic, K. y Woodworth, S. (1995). Personality and parenting: Exploring the mediating role of transient mood and daily hassles. Journal of Personality, 63, 905-929.

Bjorkqvist, K., Largerspetz, K.M. y Kaukiainen, A. (1992). Do girls manipulate and boys fight? De- velopmental trends in regard to direct and indirect aggression, Aggressive Behavior, 18, 117-127.

Bosacki, S. (2003), Psychological pragmatics in preadolescents: Sociomoral understanding, self-worth, and school behavior. Journal of Youth y Adolescence, 32, 141-155.

Bronfenbrenner, U. (1958). Socializatrion and social class through time and the space. En E.E. Maccoby, T.M. Newcomb y E.L. Harley (Eds.). Readings in social psychology. New York: Henry Holt y Co.

Bronfenbrenner, U. (1974 a). Development research, public policy, and the ecology of childhood. Child Development, 45, 1-5.

Bronfenbrenner, U. (1979).The Ecology of Human Development. Experiments by nature and design. Cambridge, M.A.: Harvard University Press.

Burgental, D.B., Love, L.R. Kaswan, J.J. y April, C. (1975). Verbal non-verbal conflict in parental messages to normal and disturbed children. Journal of Abnormal Psychology, 77, 6-10.

Buss, A. H. (1995). Personality: Temperament, social behavior and self. Needhamm Heits, Mass, Allyn y Bacon.

Campbell, A. y Muncer, S. (1994). Sex differences in aggression: social representation and social roles. British Journal of Social Psychology, 33, 233240.

Campbell, A., Sapochnik, M. y Muncer, S. (1997). Sex differences in aggression: does social representation mediate form of aggression. British Journal of Social Psychology, 161-171.

Caprara, G.V. y Pastorelli, C. (1989). Toward a reorientation of research on aggression. European Journal of Personality, 3, 121-138.

Caprara, G.V., Barbaranelli, C. y Comrey, A.L. (1992). A personological approach to the study of aggression. Personality and Individuality Differences, 13, 77-84.

Caprara, G.V., Barbaranelli, C. y Zimbardo, P. (1996). Understanding the complexity of human aggression: affective, cognitive, and social dimensions of individual differences in propensity toward aggression. European Journal of Personality, 10, 133155. 
Caprara, G.V., Manzi, J. y Perugini, M. (1992). Investigating guilt in relation to emotionality and aggression. Personality and Individuality Differences, 13, 519-532.

Caprara, G.V. y Pastorelli, C. (1993). Early emotional inestability, prosocial behaviour and aggression: some methodological aspects. European Journal of Personality, 7, 19-36.

Carrasco, M.A. y del Barrio, V. (2002). Evaluación de la autoeficacia en niños y adolescentes. Psicothema, 14, 323-332.

Carrasco, M.A. y del Barrio, V. (2003). Self-efficacy and anger expression and coping in Spanish children. Presentado en la mesa de "Temas sobre la niñez del $4^{\circ}$ Congreso Iberoamericano de Evaluación Psicológica. Perú, Lima 11, 12 de julio, (Pág. 78).

Cillessen, A., Van Ijzendoon, H. y Van Lieshout, C.(1992). Heterogeneity among peer-rejected boys: Subtypes and stabilities. Child Development, 63, 893-905.

Conger, R.D., Conger, K.J., Elder, G.H., Jr., Lorenz, F., Simons, R. y Whitbeck, L. (1992). A Family process model of economic hardship and adjustment of early adolescent boys. Child Development, 63, 526-541.

Conger, R.D., Conger, K.J., Elder, G.H., Jr., Lorenz, F., Simons, R. y Whitbeck, L. (1993). Family economic stress and adjustment of early adolescent girls. Developmental Psychology, 29, 206-219.

Constantino, J.N.(1996): Attachment and aggression among children of the working poor. En C.F. Ferris y T. Grisso, Understanding aggressive behavior in children. New York, The New York Academy of Sciences.

Coopersmith, S.(1967) The antecedents of self-Esteem. San Francisco: Freeman.

Crick, N.R. (1997). Engagement in gender normative versus non-normative forms of aggression: links to social-psychological adjustment. Developmental Psychology, 4, 610-617.

Coren, S.(1999). Arousal predisposition as a predictor of antisocial and delinquent behavior.Personal and Individual Differences, 27, 815-820.

Crick, N., Casas, J.F. y Mosher, M. (1997). Relational and overt aggression in preschool. Developmental Psychology, 33, 579-588.
Crick, N.R. y Grotpeter, J.K. (1995). Relational aggression, gender and social psychological adjustment. Child Development, 66, 710-722.

Del Barrio, V., Mestre, V. y Carrasco, M.A. (2003). Relaciones entre empatía y agresividad, presentado en el Simposium sobre "Evaluación de problemas del comportamiento social en adolescentes" en el 29 Congreso de Interamericano de Psicología. Perú, Lima. 11-16 de Julio. CD.

Del Barrio, V., Moreno, C. y López, R. (2001). Evaluación de la agresión y la inestabilidad emocional en niños españoles y su relación con la depresión. Clínica y Salud, 13, 33-50.

Del Barrio, V., Frías, D. y Mestre, V. (1994). Autoestima y depresión en niños. Revista de Psicología General y Aplicada, 4, 471-476.

Del Barrio del Barrio, V. (1998). Educación y nuevos tipos de familia. Psicología Educativa, 4, 23-47.

Del Barrio, V., Mestre, V. y Carrasco, M.A. (2003). Relaciones entre empatía y agresividad, presentado en el Simposium sobre "Evaluación de problemas del comportamiento social en adolescentes" en el 29 Congreso de Interamericano de Psicología. Perú, Lima. 11-16 de Julio. CD.

Del Barrio, V., Aluja, A. y Spielberger, C. (2005). Manual del STAXI-N. Madrid, TEA.

Demo, D.H. y Acoch, A.C. (1988). The impact of divorce on children. Journal of Marriage and the Family, 50, 619-648.

Dodge, K.A., Pettit, G.S. y Bates, J.E. (1994). Socialization mediators of the relation between socioeconomic status and child conduct problems. Child Development, 65, 649-665.

Dodge, K.A. y Coie, J.D. (1987). Social informationprocessing factors in reactive and proactive aggression in children's peer groups. Journal of Personality and Social Psychology, 53, 1146-1158.

Dodgen, C.E. \& Shea, W.M. (2000). Sustance use disorders: assessment and treatement. San Diego, CA.: Academic Press.

Dollar, J., Doob, L.W., Miller, N.E., Mowrer, O.H. y Sears, R.R. (1939). Frustration and Aggression. New Haven, CT.: Yale University Press.

Donnerstein, E. (2003). Medios de comunicación. En J. Sanmartín (Coord.), El laberinto de la violencia, Barcelona: Ariel. 
Dornbusch, S., Ritter, P., Liederman, P., Roberts, D. y Fraleigh, M. (1987). The relation of parenting style to adolescent school performance. Child Development, 58, 1244-1257.

Edems, J. (1999). Aggressive children's self-systems and the quality of their relationships with significant others. Agression and violence behavior, 4, 151-177.

Egeland, B., Pianta, R. y O’Brien, M. (1993): Maternal intrusiveness in infant and child maladaptation in early school years. Developmental and Psychopathology, 5, 359-370.

Egeland, B., Jacobvitz, D. y Stroufe, L.A. (1988). Breaking the cycle of abuse. Child Development, 59, 1080-1088.

Eisenberg, N., Fabes, R.A., Murphy, B., Karbon, M. Smith, M. et al. (1996). The relations of children's dispositional empathy-related responding to their emotionality, regulation, and social functioning. Developmental Psychology, 32,195-209.

Eisenberg, N. y Strayer, J. (1987). La empatía y su desarrollo. Bilbao: Desclée de Brouwer.

Eme, R. (1979). Sex differences in childhood psychopathology: A review. Psychological Bulletin, 92, 310-330.

Erel, O., y Burman, B. (1995). Interrelatedness of marital relations and parent child relations: A metaanalytic review. Psychological Bulletin, 118, 108132.

Erikson, E. (1968). Identity: Youth and crisis. Oxford, England: Norton y Co.

Eron, L. (1963). Relationship of TV viewing habits and aggressive behavior in children Journal of Abnormal and Social Psychology, 67, 193-196.

Eron, L., Lefkowitz, M. y Walder, L. (1973). Does television violence cause aggression? American Psychologist, 27, 253-263.

Evans, G.(2004). The environment of childhood poverty. American Psychologist, 59, 77-92.

Eysenck, H.J. y Eysenck, S. (1975). Manual for the Eysenck Personality Questionnaire. Sevenoaks: Hodder y Stoughton. London.

Eysenck, H.J. y Gudjonsson, G. (1989). The causes and cures of criminality. New York, US: Plenium Press.
Eysenck, S.B., Eysenck, H.J. y Barrett (1985). A revised version of the psychoticism scale. Personality and Individual Differences, 6, 21-29.

Eysenck, S.B. y Eysenck, H.J. (1963). On the dual nature of extraversion. British Journal of Social and Clinical Psychology, 2, 46-55.

Farrell, A., Kung, E., White, K. y Valois, R. (2000). The structure of self reported aggression, drug use, and delinquent behaviors during early adolescence. Journal of Clinical Child Psychology, 29, 282-292.

Fries, M.E. (1937). Factors in character development, neuroses, psychoses and delinquency. American Journal of Orthopsychiatry, 7, 142-181.

Funk, J., Hagan, J. y Schimming, J. (2002). Aggression and Psychopathology in Adolescent with a preference for violent electronic games. Aggressive Behavior, 28, 134-144.

Furmham, A. (1983). Political Knowledge and awareness in adolescents. Journal of Adolescent, 6, 373-385.

Galen, B.R. y Underwood, M.K. (1997). A developmental investigation of social aggression among children. Developmental Psychology, 33, 589-600.

Goeting, A. (1994). The parenting-crime connection. Journal of Primary Prevention, 14,169-186.

Gray, J. A. (1991). The neuropsychology of temperament. In J. Strelau \& A. Angleitner (Eds.). Explorations in temperament: perspectives on theory and measurement (pp. 105-128. New York: Plenum.

Graziano, W., Willians, G., Hair, E., Jensen. Campbell, L. y Finch, J. (1997). The self a mediator between personality and adjustment. Journal of Personality and Social Psychology, 73, 392-404.

Guerra, N.G., Huesmann, L.R. Tolan, P.H. y Acker, R.V., Eron, L.D. (1995). Stressful events and individual beliefs as correlates of economic disadvantage and aggression among urban Children. Journal of Consulting and Clinical Psychology, 63, 518-528.

Heaven, P. (1994). Personality factors and preferences for therapy: A simulated study among a community sample of adults. Australian Psychologist, 29, 207-211. 